\title{
Keeping an Engineering Economy Course In-line With the Practice of Engineering
}

\author{
William R. Peterson, PhD, and Guanghsu Chang, $\mathrm{PhD}$ \\ Department of Automotive and Manufacturing Engineering Technology \\ Minnesota State University, Mankato
}

\begin{abstract}
:
This paper addresses a perceived gap between the use of spreadsheets in the application of engineering economy concepts and tools in the classroom and in the workplace. Of particular concern is the use of tables in teaching the material and their absence from the workplace. The paper is based on the authors' experience in the workplace as practicing engineers/engineer managers and in the classroom teaching engineering economy at both the graduate and undergraduate levels. The authors also present the results of teaching the course using spreadsheets exclusively.
\end{abstract}

\section{Background:}

As suggested earlier, the use of spreadsheets for engineering economic type calculations is the norm in the workplace ${ }^{1}$. Even in 1980 practitioners were writing simple programs in Basic and other programing languages to calculate internal rates of return (IRR). In one instance which one of us was involved with, the calculations were done on a single board computer (an AIM 65). In this instance once the program had been written and saved, all that was required was the an input of the annual cash flows associated with a project and then a simple "do loop" was incremented until the net present worth was zero (assuming that the project started out at an interest rate of zero and gave a positive value. While seemingly crude, it allowed the cash flows to be irregular (which is extremely common in practice) and (assuming correct input of the cash flows) did not make math errors. While the program could have been made faster by a "better" search algorithm, it met the needs of the using organization.

At the same time, "MBA" (Masters of Business Administration) hand-held calculators were becoming available to do basic financial calculations such as find the payment on a loan (P) with interest (i) and period (n) based on the same underlying calculation in the tables is as a lookup value for "A/P, i, n".

By 1990 spreadsheets, such as Lotus 1,2, 3 and Quattro, were readily available on personal computers (and larger computers) with built in financial sub-routines (which basically calculated the factor based on the $\mathrm{i}$ and $\mathrm{n}$ and then did the multiplication). There was even a subroutine to find IRR based on a cash flow (which basically did the same incremental search as in the AIM 65 example.

Engineering Economy continues to use the table approach with the texts being based on the tables with supplements and extensions in the chapters to address the use of spreadsheets (typically Excel). This has several reasons, but the most valid one in our opinion is that the Fundamentals of Engineering (FE) Exam is setup to use the tables for the engineering economy problems. 


\section{An Engineering Economics Course without Tables}

Teaching and engineering economic course without the use of tables requires that certain issues be addressed in course preparation and design. These issues include:

1. If the students are to eventually take the FE exam, how will they be prepared to use tables to address the problems they will need to do on it?

2. How will the students access the spreadsheets in the classroom?

3. What text will be used since the texts use the tables?

4. What are the outcomes desired?

In the course we designed (and in an interim course in which project management and engineering economics were combined) we addressed these issues as follows.

The environment in which our course was offered was in an engineering technology program in a state where the engineering technology students are not automatically eligible to take the FE exam. Thus to a certain degree, Issue 1 above is not relevant. But to address this issue in a wider context, many programs do not include a course in engineering economics which covers $8 \%$ of the exam for industrial and mechanical engineers for example ${ }^{3}$. These programs typically rely on the material need to do the engineering economy problems on the FE being covered in one session (3 hours more or less) of a review/preparation course. This seems to work to the extent needed for the FE.

As to Issue 4 above, assuming the outcomes do not include Issue 1, the FE exam, then may vary. The ones for the course we were designing are as follow (the course was titled "Project Valuation"):

1. Explain the role of Engineering Value Analysis and it's connection to Project Management

2. Identify types of projects incorporating value analysis, such as make vs buy, new product design and development, product and process improvement, facility and infrastructure

3. Understand costing approaches and applications such as activity based costing versus traditional costing

4. Discuss and apply the concept of Overall Equipment Effectiveness (OEE)

5. Measure the project outcomes to organizational goals of cost, quality/performance and time.

6. Create and apply payback models and analysis

7. Develop Learning Curves and for their systematic cost influence

8. Gather key inputs for a capital project justification (CJP) proposal

9. Identify project evaluation techniques to include NPV and IRR

10. Assess, calculate, and apply the time value of money

11. Investigate, present, and discuss industry investment alternatives

12. Prepare and present a persuasive oral and written Capital Justification Proposal

While items 1, 4, and 5 above are course specific, item 10 is the cornerstone of engineering economy, and it is hard to imagine an engineering economy course without items 6 and 9. Items $3,7,8$, and 11 are items which should be most engineering economy courses, and items 8 and 12 are why we offer the course. At the awarding of the degree this is where the graduate will use what he/she learned. This is also why we believe spreadsheets are a better approach since we can use real world problems which have irregular cash flows in lieu of the regular cash flows in 
standard text problems. We can use geometric gradients which seem to occur in practice in lieu of the contrived arithmetic gradients which we can handle with tables but do not see in practice. Additionally, in practice the major effort is represented by item 8 which in the typical text is given and is implied to be trivial.

Items 6, 9 and 10 are where spreadsheet calculations are done in lieu of tables and where this particular course approach differs from one using tables. While students need to understand the underpinning of what they are doing when they use a program (in order to ascertain of the "number" output makes sense) this can be as easily done with spreadsheets as with tables and maybe with more meaning since the basis is simpler - ever cash flow entry $\left(\mathrm{CF}_{\mathrm{n}}\right)$ is worth, in terms of present value $\left(\mathrm{PV}_{\mathrm{n}}\right), \mathrm{CF}_{\mathrm{n}} /(1+\mathrm{MARR})^{\mathrm{n}}$, where MARR (Minimum Attractive Rate of Return) is the interest rate which makes an investment valuable. This equation can be used to learn the concept prior to moving on to the functions (which do the non-value added programing/calculations - just like the tables).

This is where issue 3, which text book to use, becomes relevant. Since the text builds knowledge off of the use of the tables to solve problems, even if the lecture does not use tables, the supplied resource does and this is where the typical student goes to walk thru a homework problem. Having used a book as a supplement previously, we decided to not use a text book for this course. This is not a valid solution for all. In this instance the instructor had taught the course for over 15 years and writes in the area. Since engineering economy is typically as service course and assigned as such, for this approach to work universally, a text will need to be developed for many instructor to be comfortable with this approach.

Issue 2 probably requires either a computer classroom or access to a laptop by each student. In this instance the course was taught in a computer classroom with one computer per student. This should be less and less of a factor as we believe the laptop (or its equivalent) will soon replace the graphing calculator as the standard tool for an engineering student (just as the slide rule once was).

\section{Teaching the Course}

The course has been taught twice (Fall 2010 and Fall 2011) without a text and using spreadsheets as the tool for problem solving. Both semesters case problems ${ }^{2}$ were used as a significant source of problems. The first offering had twelve students and the second had six - all in the program who were eligible. While these were small classes, in actuality the class of twelve was easier to teach than the class of six and 20 to 25 would be acceptable (we have taught other hands-on classes to include programing classes with these numbers).

The grade outcomes were normal (one $\mathrm{D}$ and one $\mathrm{F}$ in the first offering with both grades reflect not taking one of the three exams in the course - one student dropped the class in the second offering) with average grades of $\mathrm{B}+$ and $\mathrm{B}$. The learning/knowledge outcomes were judged to be good. The course evaluations by the students were 3.90 and 4.20 (out of 5). 


\section{Bibliography}

1. Peterson, William R., Rafael E. Landaeta, and Bryan Magary, "Is It Time For A New Paradigm?", 2005 ASEE Annual Conference and Exposition Proceedings (June 12 - 15, 2005, Portland, Oregon), American Society for Engineering Education, Session 2639 (CD-ROM)

2. Peterson, William R., and Ted G. Eschenbach, Cases in Engineering Economy, Second Edition, Oxford University Press, New York, 2009

3. http://www.ncees.org/Exams/FE_exam.php (retrieved 10/7/2011)

\section{GUANGHSU CHANG}

Dr. Guanghsu A. Chang is a professor of the Automotive and Manufacturing Engineering Technology Department at Minnesota State University, Mankato. His research interests involve the study of robotic applications, manufacturing automation, Design for Assembly (DFA), and Case-Based Reasoning (CBR) applications. He holds both MSIE and Ph.D. degrees from the University of Texas at Arlington.

\section{WILLIAM R. PETERSON}

Dr. Bill Peterson is currently an associate professor at Minnesota State University, Mankato. He holds a BIE from Auburn University. He spent twenty years in industry during which time he earned an MBA. He has spent the last twenty teaching industrial and manufacturing engineering, engineering management, and the management of technology. He is a past president of SEMS and ASEM and the co-author of a book of case problems. 